\title{
Comparison of Clinical Outcomes in Patients Undergoing a Salvage Procedure for Thrombosed Hemodialysis Arteriovenous Grafts
}

\author{
You Kyeong Park, M.D., Jae Woong Lim, M.D., Chang Woo Choi, M.D., Keun Her, Ph.D., Hwa Kyun Shin, Ph.D., \\ Sung Ho Shinn, M.D. \\ Department of Thoracic and Cardiovascular Surgery, Soonchunhyang University Bucheon Hospital, Soonchunhyang University College of Medicine, Bucheon, Korea
}

\section{ARTICLE INFO}

Received June 17, 2021

Revised August 4, 2021

Accepted September 8, 2021

Corresponding author

Chang Woo Choi

Tel 82-32-621-5307

Fax 82-32-621-5016

E-mail tcvsccw@schmc.ac.kr

ORCID

https://orcid.org/0000-0002-8042-7447
Background: The major limitation of arteriovenous graft access is the high incidence of thrombotic occlusion. This study investigated the outcomes of our salvage strategy for thrombosed hemodialysis arteriovenous grafts (including surgical thrombectomy with balloon angioplasty) and evaluated the efficacy of intragraft curettage.

Methods: Salvage operations were performed for 290 thrombotic occluded arteriovenous grafts with clinical stenotic lesions from 2010 to 2018. Of these, 117 grafts received surgical thrombectomy and balloon angioplasty from 2010 to 2012 (group A), and 173 grafts received surgical thrombectomy and balloon angioplasty, with an additional salvage procedure using a curette and a graft thrombectomy catheter, from 2013 to 2018 (group B). Outcomes were described in terms of post-intervention primary patency and secondary patency rates.

Results: The post-intervention primary patency rates in groups A and B were $44.2 \%$ and $66.1 \%$ at 6 months and $23.0 \%$ and $38.3 \%$ at 12 months, respectively ( $p=0.003$ ). The post-intervention secondary patency rates were $87.6 \%$ and $92.6 \%$ at 6 months and $79.7 \%$ and $85.0 \%$ at 12 months, respectively ( $p=0.623$ ). Multivariate Cox regression analysis demonstrated that intragraft curettage was a positive predictor of post-intervention primary patency (hazard ratio, 0.700; 95\% confidence interval, 0.519-0.943; $p=0.019$ ).

Conclusion: Surgical thrombectomy and balloon angioplasty showed acceptable outcomes concerning post-intervention primary and secondary patency rates. Additionally, intragraft curettage may offer better patency to salvage thrombotic occluded arteriovenous grafts with intragraft stenosis.

Keywords: Surgical arteriovenous shunt, Vascular graft occlusion, Thrombectomy, Shunts

\section{Introduction}

Recent topics related to vascular access for end-stage kidney disease include "Life-Plan" related concepts, guidance concerning vascular access choice, and the management of specific complications [1]. The National Kidney Foundation Kidney Disease Outcomes Quality Initiative (NKF-K/DOQI) Clinical Practice Guidelines consistently recommend the preferential placement of arteriovenous fistulas over arteriovenous grafts (AVGs). However, the need for prosthetic arteriovenous access is increasing with older age in end-stage kidney disease patients, as well as with the increasing prevalence of comorbidities (e.g., hypertension, diabetes, and vascular disease) [2]. The major limitation of AVG access is the high incidence of thrombotic occlusion and the shorter patency compared with arteriovenous fistulas. Salvage procedures for thrombosed prosthetic access are performed either surgically (surgical thrombectomy with patch angioplasty or jump bypass) or using an endovascular technique. Endovascular treatment has become popular because of its less invasive nature and relative ease. Percutaneous mechanical thrombectomy and pharmacological thrombolysis have historically been used for percutaneous thrombus removal, but the results are in- 
ferior to those of surgical thrombectomy $[3,4]$. Percutaneous mechanical thrombectomy produces acceptable results for thrombosed AVGs, but it causes complications such as vessel injury, arterial embolization, and hemolysis $[5,6]$. Endovascular thrombolytic therapy with urokinase has a high rate of technical failure necessitating surgery and a substantially higher cost, along with systemic bleeding complications [7].

After surgical or endovascular treatment of graft thrombosis to ensure continuing graft function, treatment of the stenotic lesion is essential, because it is the most common cause of thrombotic occlusion. Surgical revision of these stenotic lesions, such as patch angioplasty or jump bypass, is usually followed by surgical thrombectomy. Our strategy is based on a "hybrid" approach combining surgical thrombectomy and endovascular treatment that has produced good results $[8,9]$. Although various treatment options are available, the post-intervention primary patency rates after salvage procedures remain a challenge, with reports of $34 \%-63 \%$ at 6 months and $13 \%-49 \%$ at 12 months [4,7-12].

Our strategy to relieve the intragraft neointimal hyperplasia causing early re-obstruction was direct removal of the neointimal overgrowth and plaque of the graft using a Volkman bone curette, additional thrombectomy using a Fogarty Graft Thrombectomy Catheter (Edwards Lifesciences, Irvine, CA, USA); and balloon angioplasty. This study investigated the outcomes of our hybrid procedure and evaluated the efficacy of intragraft curettage and a graft thrombectomy catheter for thrombosed AVGs.

\section{Methods}

\section{Patients}

This study included patients with clinical evidence of a malfunctioning AVG between 2010 and 2018: graft malfunction was suggested by a physical examination (no thrill), an inability to maintain dialysis, or the absence of blood flow on an ultrasound examination. In total, 1,871 thrombosed accesses in 1,705 patients were screened; 290 thrombosed accesses were enrolled. This retrospective study was approved by the Institutional Review Board of Soonchunhyang University Bucheon Hospital (2021-05-21001). The requirement for informed consent from individual patients was omitted since it was to be conducted on existing anonymous data from previous years. The inclusion criteria and exclusion criteria are listed in Table 1. The graft was implanted in the upper limb for at least 3 months
Table 1. Inclusion and exclusion criteria

\begin{tabular}{ll}
\hline \multicolumn{1}{c}{ Inclusion criteria } & Exclusion criteria \\
\hline $\begin{array}{l}\text { Prosthetic AV graft in the } \\
\text { upper limb }\end{array}$ & Follow-up loss $<1$ mo \\
$\begin{array}{l}\text { Prosthetic AV graft } \\
\text { implanted for }>3 \text { mo }\end{array}$ & $\begin{array}{c}\text { Occluded AV grafts due to } \\
\text { infection }\end{array}$ \\
Thrombotic occluded AV & Occluded AV grafts due to \\
graft with clinical evidence & another thrombogenic \\
of a stenotic lesion & condition (e.g., atrial fibrillation) \\
\hline
\end{tabular}

$\mathrm{AV}$, arteriovenous.

before thrombotic occlusion. Grafts obstructed by other thrombogenic conditions or other causes (e.g., infection) were excluded; thrombosed grafts with clinical evidence of a stenotic lesion were enrolled. Patients were excluded if they received surgical revision, such as patch angioplasty, jump bypass, or partial graft interposition.

Patients were divided into 2 groups based on the treatment method: group A, surgical thrombectomy and balloon angioplasty (performed from 2010 to 2012); and group $B$, surgical thrombectomy and balloon angioplasty, with additional salvage procedure using a curette and graft thrombectomy catheter (performed from 2013 to 2018). Medical records were reviewed to obtain patient demographics, medical history, graft age, access location, graft anatomy, previous interventional history, stenotic lesion operative details, and follow-up data (Table 1). The stenotic lesion data contained the lesion location, lesion length, angioplasty balloon diameter, and previous stents in the venous tract or central vein.

\section{Definitions}

Post-intervention primary patency was defined as the interval from the index intervention until thrombosis or any intervention used to maintain patency, or the patency measurement time. Post-intervention secondary patency was defined as the interval from the time of the index intervention until access abandonment or the time of patency measurement. Graft abandonment was defined as the need for transition to alternative access (e.g., hemodialysis catheter or alternative access) or method of dialysis (e.g., peritoneal dialysis). Other reasons for abandonment, such as infection or renal transplant, were censored. Procedural failure was defined as the inability to use the access for at least 1 hemodialysis session [13]. Anastomotic stenosis was defined as stenosis $>50 \%$, as demonstrated by fistulography after thrombectomy. Intragraft stenosis was defined as stenosis occurring within a prosthetic graft distant from the anas- 
tomosis site. Central vein stenosis was defined as stenosis at a major intrathoracic vein, including the subclavian vein, innominate vein, or superior vena cava.

\section{Operative methods}

Ultrasonography was performed before the operation to determine the location of the stenotic lesion. A small skin incision was made along the graft with the patient under local anesthesia; graftotomy was performed at the apex of the U-shaped graft or the middle part of the straight-type graft. A Fogarty (Edwards Lifesciences) arterial embolectomy catheter was used to remove the thrombus. Following thrombus removal, intraoperative fistulography from the arterial inflow to the superior vena cava was performed and balloon angioplasty was performed for the stenotic lesion. Insufficient dilatation of severe stenotic lesions was managed in several cases with a stent for venous anastomosis stenosis, venous outflow tract stenosis, or central vein stenosis. Starting in 2013, additional mechanical thrombectomy was performed using a graft thrombectomy catheter to remove the remnant thrombus in the AVG. Intragraft curettage was performed to remove neointimal hyperplasia slightly away from the anastomosis site. Fibroblastic ingrowth at a needle puncture site was the main target of curettage. To the extent possible, curettage was not performed for neointimal hyperplasia at the anastomosis site due to the possible risk of rupture. Fistulography in the operative field was simultaneously performed to confirm the remnant lesions, followed by balloon angioplasty.

\section{Follow-up}

All patients were examined 2 weeks after the revision, as recommended by the NKF-K/DOQI guidelines. Thereafter, patients underwent clinical follow-up in accordance with the recommendations of the surgeon or nephrologist. Follow-up surveillance included a physical examination, measurements of venous pressure at each hemodialysis session, and duplex ultrasonography examination of access by the surgeon. Follow-up angiography was only performed if there was evidence of clinical or hemodynamic abnormalities.

\section{Statistical analysis}

Data were entered into IBM SPSS ver. 20.0 (IBM Corp., Armonk, NY, USA) for analysis. The Student t-test and the Pearson chi-square test were used to determine differences between the 2 groups. Kaplan-Meier survival analysis and the log-rank test were used to determine primary and secondary patency rates. Univariate and multivariate Cox proportional hazards regression analyses were used to estimate prognostic factors influencing post-intervention primary and secondary patency rates. Predictive factors with a $\mathrm{p}$-value $<0.20$ in the univariate analysis were included in multivariate regression for adjustment. A p-value $<0.05$ was considered to indicate statistical significance.

\section{Results}

\section{Patient characteristics}

In total, 290 grafts were included in the study, of which 117 grafts were treated by surgical thrombectomy and balloon angioplasty (group A) and 173 received an additional salvage procedure using a curette and a graft thrombectomy catheter (group B) (Fig. 1). Table 2 summarizes patients' demographic characteristics. The mean ages of the patients were $63.4 \pm 13.2$ years and $67.9 \pm 12.8$ years in groups $A$ and $B$, respectively $(\mathrm{p}=0.004)$. No significant differences in sex, hypertension, diabetes, or history of antiplatelet and warfarin therapy were observed between the 2 groups. The grafts tended to be older in group B (37.8 \pm 35.2 months) than in group A $(32.5 \pm 28.0$ months $)(p=0.184)$ (Table 2). The most common location for the stenotic lesion was the venous anastomosis site in both groups. The mean diameter of the balloon was $7.2 \pm 0.7 \mathrm{~mm}$ in group $\mathrm{B}$, which was significantly larger than the mean diameter in group $\mathrm{A}$ $(6.9 \pm 0.8 \mathrm{~mm})(\mathrm{p}=0.002)$. Two patients in group A had previous stents in the venous tract, whereas 16 patients in group B had previous stents (1.8\% versus 9.2\%, $\mathrm{p}=0.011)$. The number of previous interventions was $1.3 \pm 1.7$ in group $\mathrm{A}$ and $1.7 \pm 1.8$ in group $\mathrm{B}(\mathrm{p}=0.033)$ (Table 3 ).

\section{Procedural results}

Procedural failure occurred in 5 and 4 patients in groups $A$ and $B$, respectively. Common causes of re-intervention during the follow-up period included thrombotic occlusion, difficulty achieving hemostasis after hemodialysis, arm swelling, high venous pressure during dialysis, and reduced total access flow rate, as determined by duplex ultrasonography. The post-intervention primary patency rates for group A were $44.2 \%$ and $23.0 \%$ at 6 and 12 months, respectively. The post-intervention primary patency rates for group B were $66.1 \%$ and $38.3 \%$ at 6 and 12 months, respectively. Kaplan-Meier plots of the 12 -month post-interven- 


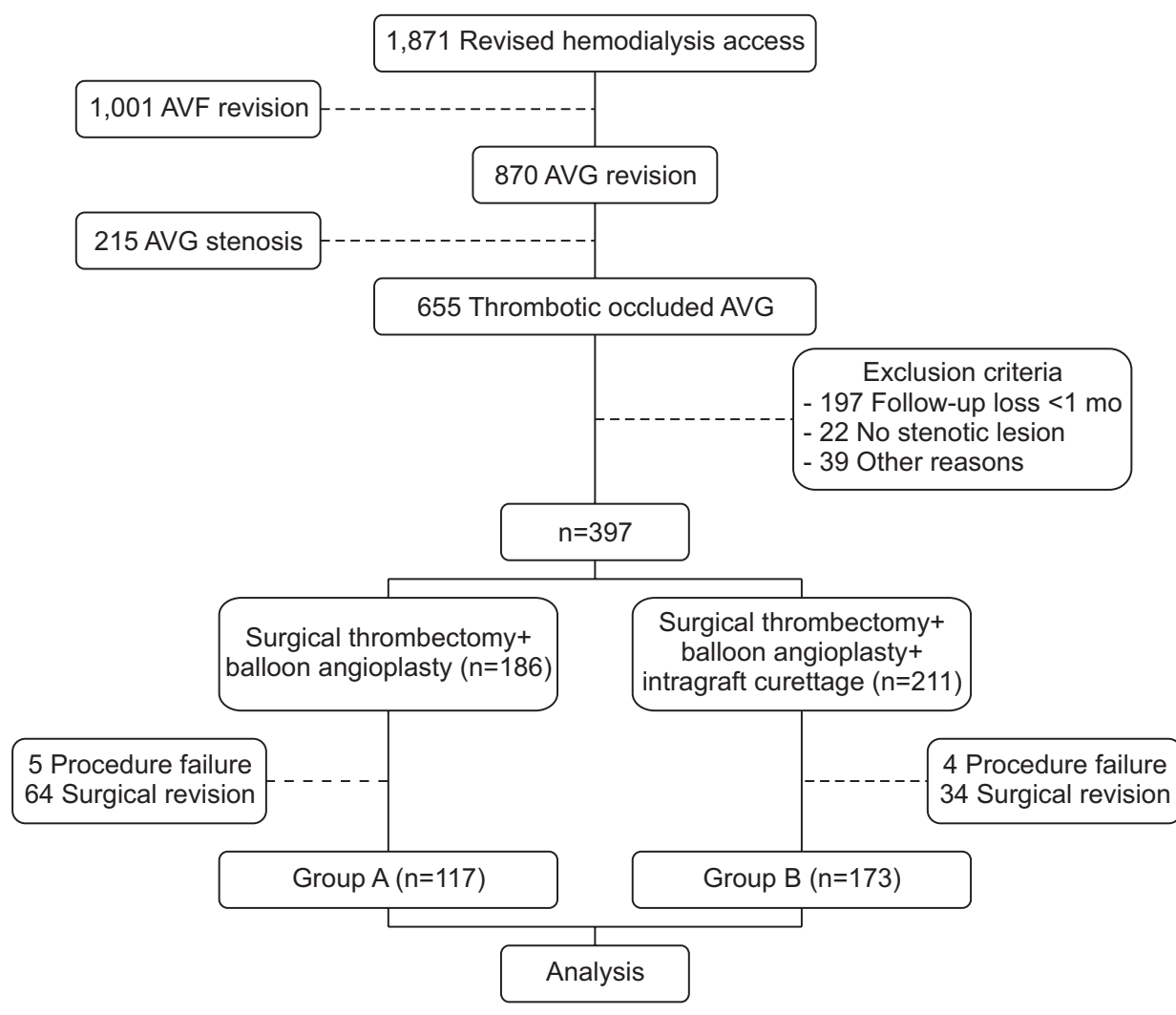

Fig. 1. Flow diagram of the study. AVG, arteriovenous graft.
Table 2. Demographic and clinical characteristics of the patients according to the treatment group

\begin{tabular}{lccc}
\hline \multicolumn{1}{c}{ Characteristic } & $\begin{array}{c}\text { Group A } \\
(\mathrm{n}=113)\end{array}$ & $\begin{array}{r}\text { Group B } \\
(\mathrm{n}=173)\end{array}$ & p-value \\
\hline $\begin{array}{c}\text { Demographic and } \\
\text { medical history }\end{array}$ & & & \\
Age $(\mathrm{yr})$ & $63.4 \pm 13.2$ & $67.9 \pm 12.8$ & 0.004 \\
Sex, female & $52(46)$ & $77(44.5)$ & 0.802 \\
Hypertension & $88(77.9)$ & $136(78.6)$ & 0.883 \\
Diabetes mellitus & $76(67.3)$ & $112(64.7)$ & 0.661 \\
Antiplatelet therapy & $60(69.8)$ & $111(70.7)$ & 0.879 \\
Warfarin therapy & $6(7.0)$ & $23(14.6)$ & 0.078 \\
Graft data & & & \\
Graft age (mo) & $32.5 \pm 28.0$ & $37.8 \pm 35.2$ & 0.184 \\
Left arm & 84 & 139 & 0.231 \\
\hline Right arm & 29 & 34 & 0.231 \\
\hline Forearm & 87 & 136 & 0.852 \\
\hline Upper arm & 25 & 37 & 0.852 \\
\hline Anastomosed vein & & & 0.878 \\
Cephalic vein & 2 & 5 & \\
Basilic vein & 20 & 31 & \\
Cubital vein & 44 & 72 & \\
Brachial vein & 23 & 36 & \\
Axillary vein & 24 & 29 & \\
\hline
\end{tabular}

Values are presented as mean \pm standard deviation or number (\%).
Table 3. Summary of stenotic lesion characteristics

\begin{tabular}{|c|c|c|c|}
\hline Variable & $\begin{array}{l}\text { Group A } \\
(n=113)\end{array}$ & $\begin{array}{l}\text { Group B } \\
(n=173)\end{array}$ & $\mathrm{p}$-value \\
\hline \multicolumn{4}{|l|}{ Location of stenotic lesion } \\
\hline Venous anastomosis site & $78(69.0)$ & $125(72.3)$ & 0.557 \\
\hline Outflow venous tract & $57(50.4)$ & $73(42.2)$ & 0.171 \\
\hline Arterial anastomosis site & $16(14.2)$ & $14(8.1)$ & 0.102 \\
\hline Intragraft & $52(46.0)$ & $88(50.9)$ & 0.423 \\
\hline Central vein & $9(8.0)$ & $16(9.2)$ & 0.707 \\
\hline Length of lesion & & & 0.274 \\
\hline Short $(<4 \mathrm{~mm})$ & $68(60.2)$ & $92(53.2)$ & \\
\hline Long (>4 mm) & $45(39.8)$ & $81(46.8)$ & \\
\hline Balloon diameter & $6.9 \pm 0.8$ & $7.2 \pm 0.7$ & 0.002 \\
\hline Existing venous tract stent & $2(1.8)$ & $16(9.2)$ & 0.011 \\
\hline Existing central vein stent & $5(4.4)$ & $4(2.3)$ & 0.490 \\
\hline No. of previous interventions & $1.3 \pm 1.7$ & $1.7 \pm 1.8$ & 0.033 \\
\hline
\end{tabular}

tion primary patency rates are shown in Fig. 2. The postintervention primary patency rates were significantly better in group B than in group A at 6 and 12 months $(\mathrm{p}<0.001)$.

Clinical variables associated with post-intervention primary and secondary patency rates were analyzed through 
univariate and multivariate Cox proportional hazards regression. Multivariate Cox proportional hazards regression analysis indicated that an existing venous tract stent was a significant predictor of decreased primary patency after adjustment for potential confounding factors (hazard ratio [HR], 1.813; 95\% confidence interval [CI], 1.013-3.245; $\mathrm{p}=0.045)$. Intragraft curettage was a significant predictor of primary patency $(\mathrm{HR}, 0.700 ; 95 \% \mathrm{CI}, 0.519-0.943$; $\mathrm{p}=$ 0.019) (Table 4).

Group B showed a tendency for a higher post-intervention secondary patency rate than that of group A (group A: $87.6 \%$ and $79.7 \%$ at 6 and 12 months, respectively; group B:

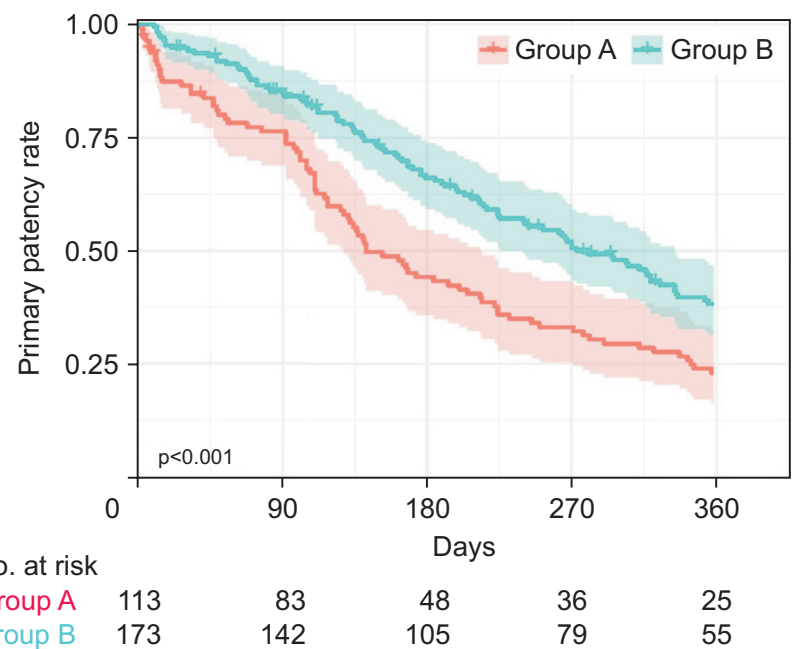

Fig. 2. Kaplan-Meier analyses of the post-intervention primary patency rate.
92.6\% and $85.0 \%$ at 6 and 12 months, respectively), but the difference between groups was not statistically significant $(\mathrm{p}=0.623)$ (Fig. 3). Multivariate Cox proportional hazards regression analysis revealed that post-intervention secondary patency, existing central vein stenosis (HR, 4.113; 95\% CI, 1.443-11.721; $\mathrm{p}=0.008$ ), and location of the graft (upper arm/forearm) (HR, 1.749; 95\% CI, 1.040-2.941; $\mathrm{p}=0.035$ ) were significant predictors of graft abandonment. Intragraft curettage was not predictive of secondary patency (Table 5).

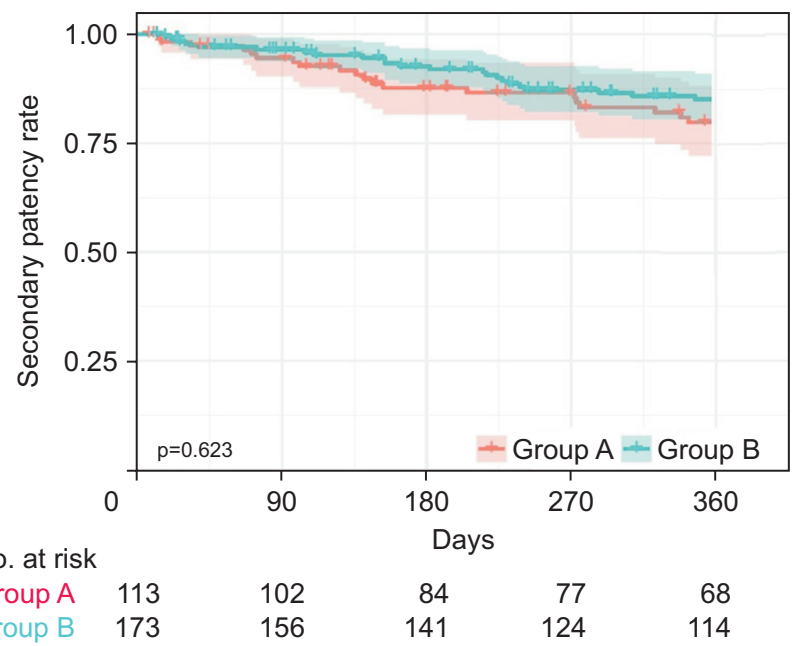

Fig. 3. Kaplan-Meier analyses of the post-intervention secondary patency rate.

Table 4. Univariate and multivariate Cox regression analysis of prognostic factors for the post-intervention primary patency of salvaged grafts

\begin{tabular}{|c|c|c|c|c|}
\hline \multirow{2}{*}{ Variable } & \multicolumn{2}{|c|}{ Univariate model } & \multicolumn{2}{|c|}{ Multivariate model } \\
\hline & $\mathrm{HR}(95 \% \mathrm{Cl})$ & p-value & $\operatorname{HR}(95 \% \mathrm{Cl})$ & p-value \\
\hline Age & $1.006(0.997-1.016)$ & 0.209 & & \\
\hline Sex (female) & $0.990(0.770-1.272)$ & 0.936 & & \\
\hline Hypertension & $0.779(0.575-1.052)$ & 0.103 & $0.742(0.525-1.050)$ & 0.092 \\
\hline Diabetes mellitus & $1.198(0.918-1.563)$ & 0.184 & $1.266(0.927-1.729)$ & 0.138 \\
\hline Graft age (mo) & $0.995(0.991-0.999)$ & 0.015 & $0.995(0.990-0.999)$ & 0.024 \\
\hline Antiplatelet therapy & $0.936(0.697-1.258)$ & 0.661 & & \\
\hline Warfarin therapy & $1.398(0.923-2.116)$ & 0.114 & $1.360(0.881-2.100)$ & 0.165 \\
\hline Left/right arm & $0.975(0.724-1.312)$ & 0.867 & & \\
\hline Forearm/upper arm & $1.440(1.067-1.945)$ & 0.017 & $1.361(0.947-1.955)$ & 0.095 \\
\hline Length of lesion & $0.821(0.638-1.056)$ & 0.125 & $0.841(0.621-1.137)$ & 0.259 \\
\hline Balloon diameter & $0.876(0.728-1.055)$ & 0.162 & $0.912(0.741-1.121)$ & 0.381 \\
\hline Existing venous tract stent & $1.553(0.930-2.592)$ & 0.092 & $1.813(1.013-3.245)$ & 0.045 \\
\hline Existing central vein stent & $1.681(0.862-3.276)$ & 0.127 & $1.550(0.685-3.507)$ & 0.293 \\
\hline No. of previous interventions & $1.034(0.956-1.118)$ & 0.402 & & \\
\hline Intragraft curettage & $0.637(0.495-0.821)$ & $<0.001$ & $0.700(0.519-0.943)$ & 0.019 \\
\hline
\end{tabular}

$\mathrm{HR}$, hazard ratio; $\mathrm{Cl}$, confidence interval. 
Table 5. Univariate and multivariate Cox regression analysis of prognostic factors for the post-intervention secondary patency of salvaged grafts

\begin{tabular}{|c|c|c|c|c|}
\hline \multirow{2}{*}{ Variable } & \multicolumn{2}{|c|}{ Univariate model } & \multicolumn{2}{|c|}{ Multivariate model } \\
\hline & $\mathrm{HR}(95 \% \mathrm{Cl})$ & $\mathrm{p}$-value & $\operatorname{HR}(95 \% \mathrm{CI})$ & p-value \\
\hline Age & $1.004(0.988-1.019)$ & 0.650 & & \\
\hline Sex (female) & $0.923(0.616-1.384)$ & 0.699 & & \\
\hline Hypertension & $1.280(0.773-2.122)$ & 0.338 & & \\
\hline Diabetes mellitus & $1.072(0.704-1.634)$ & 0.745 & & \\
\hline Graft age (mo) & $0.995(0.991-0.999)$ & 0.015 & $1.004(0.998-1.010)$ & 0.202 \\
\hline Antiplatelet therapy & $0.739(0.468-1.166)$ & 0.193 & $0.796(0.4987-1.275)$ & 0.343 \\
\hline Warfarin therapy & $1.527(0.824-2.830)$ & 0.179 & $1.823(0.970-3.425)$ & 0.062 \\
\hline Left/right arm & $0.656(0.387-1.109)$ & 0.116 & $0.549(0.290-1.038)$ & 0.065 \\
\hline Forearm/upper arm & $2.401(1.557-3.703)$ & $<0.001$ & $1.749(1.040-2.941)$ & 0.035 \\
\hline Length of lesion & $0.994(0.662-1.492)$ & 0.977 & & \\
\hline Balloon diameter & $1.188(0.920-1.535)$ & 0.186 & $1.237(0.923-1.660)$ & 0.155 \\
\hline Existing venous tract stent & $2.238(1.160-4.321)$ & 0.016 & $1.993(0.961-4.134)$ & 0.064 \\
\hline Existing central vein stent & $2.769(1.118-6.858)$ & 0.028 & $4.113(1.443-11.721)$ & 0.008 \\
\hline No. of previous interventions & $1.062(0.946-1.192)$ & 0.306 & & \\
\hline Intragraft curettage & $0.901(0.596-1.364)$ & 0.623 & & \\
\hline
\end{tabular}

$\mathrm{HR}$, hazard ratio; $\mathrm{Cl}$, confidence interval.

\section{Complications}

Two grafts in group A ruptured at the venous anastomosis site and healed after balloon tamponade and external compression. Eight grafts ruptured at the native venous outflow tract after balloon angioplasty. One patient needed a stent-graft implantation, and 1 patient had a hematoma at the rupture site. Four grafts in group B were partially ruptured at venous segments of the graft after curettage; all healed after balloon tamponade. Five grafts ruptured at the venous anastomosis site; 3 required a stent-graft and the others healed after balloon tamponade.

\section{Discussion}

A common cause of AVG failure is thrombotic flow-related occlusion. Access surveillance to identify clinically significant stenosis and perform preemptive angioplasty before thrombotic occlusion reduces the risks of thrombosis and access loss in arteriovenous fistulas; however, it does not reduce these risks in grafts [14]. Following the occurrence of thrombotic occlusion, early surgical or percutaneous thrombectomy is recommended to minimize the need for a temporary hemodialysis catheter [9]. Several studies have shown that $>85 \%$ of thrombotic occluded AVGs have underlying hemodynamically significant $(>50 \%)$ stenosis $[15,16]$. Stenosis is most commonly observed at the venous anastomosis site, although it can also be found in the draining venous tract, central vein, feeding artery, or within the graft itself. A successful salvage oper- ation should include thrombectomy and treatment of the underlying stenosis [17]. The NKF-K/DOQI guidelines revised in 2019 recommend managing thrombosed grafts through local practice and expertise using either endovascular or open surgical approaches, considering the underlying condition and patients' preferences. At our center, thrombosed AVGs have been historically treated by surgical thrombectomy, followed by either surgical revision or balloon angioplasty. This study investigated the outcomes of a hybrid strategy of surgical thrombectomy followed by balloon angioplasty with intragraft curettage.

Based on the 2006 NKF-K/DOQI guidelines for outcomes after treatment of AVG thrombosis, a reasonable goal after percutaneous or surgical thrombectomy is a clinical success rate of $85 \%$, where clinical success is defined as the ability to use the AVG for at least 1 hemodialysis treatment. After surgical thrombectomy, post-intervention primary patency should be $50 \%$ at 6 months and $40 \%$ at 12 months [18]. In 2008, Liu et al. [17] reported that surgical thrombectomy with surgical revision resulted in a higher primary patency rate than with other treatments, including surgical thrombectomy only, simultaneous balloon angioplasty, and sequential balloon angioplasty. They reported a $29.8 \%$ primary patency rate at 12 months after surgical revision [17]. However, surgical revision has substantial limitations, including the need for an additional conduit and the technical challenges associated with a redo surgical field and restenosis of the re-anastomosis site. In 2020, Go et al. [9] reported no significant difference between a hybrid strategy and surgical revision with post-in- 
tervention primary patency rates of $34.2 \%$ versus $27.8 \%$ at 6 months and $17.5 \%$ versus $12.9 \%$ at 12 months, respectively. Our study of the hybrid strategy in group A resulted in a post-intervention primary patency rate of $44 \%$ at 6 months and $23 \%$ at 12 months; these rates were not inferior to previous findings using existing methods.

The major cause of stenosis and thrombotic occlusion of an AVG is neointimal hyperplasia of the venous anastomosis site. Previous studies have revealed that the myointimal cellular component accumulates steadily and progressively in the graft and vein. Hemodynamic stress releases platelet-derived growth factor, and shear-induced intimal injury may stimulate this response [19]. Failure occurs within a mean interval of 16 months after polytetrafluorethylene graft placement [19]. Although venous anastomosis site stenosis is the most common cause of AVG dysfunction, intragraft stenosis (i.e., stenosis occurring within the prosthetic graft distant from the anastomosis site) accounts for $28 \%$ of stenotic lesions [20]. It may develop from perigraft scar formation or fibroblastic ingrowth at a needle puncture site [21]. Conventional treatment for intragraft stenosis is replacement of the segmental graft and excision of the stenotic segment. In 2015, Bautista et al. [22] studied the benefits of percutaneous intervention on intragraft stenosis within failing and thrombosed AVGs. Intragraft stenoses were treated at a median of 20.7 months after graft creation. They reported post-intervention primary patency rates of $31 \%$ at 6 months and $17 \%$ at 12 months in thrombosed AVGs; these were slightly lower patency rates than the rates achieved in AVGs with only venous anastomotic lesions [22]. In our study, the group B patients had a high rate of intragraft stenosis (50.9\%) and graft age (37.8 \pm 35.2 months) compared with the findings in previous studies, possibly because this strategy was selectively used for old/ aged grafts. The authors currently consider the indications of intragraft curettage to be old grafts used for hemodialysis for more than 6 months or grafts with recurred thrombotic occlusion more than 6 months after previous curettage. The use of a curette and graft thrombectomy catheter could be beneficial for relieving intragraft neointimal hyperplasia in older AVGs and delay the need for creating new arteriovenous access. However, it did not show a statistically significant relationship with the secondary patency rate in our study. The authors believe that this is because the patient's condition (vascular condition, general condition, etc.) has a greater influence on the secondary patency rate than the difference in surgical methods.

Identifying the predictors of primary and secondary patency could help determine which thrombosed AVGs should be treated and which AVGs should be abandoned. In this study, despite the limited use of stents, an existing venous anastomosis site or outflow venous tract stent at the time of thrombotic occlusion were significant predictors of the loss of primary patency, indicating that graft salvage with a previous stent was difficult. Several studies have reported the benefits of stent-grafts at AVG venous anastomosis stenosis sites [12,23-25]. Calsina et al. [11] studied AVG thrombosis associated with venous anastomosis stenosis treated with open thrombectomy, a covered self-expanding stent, and high-pressure balloon angioplasty. They reported post-intervention primary patency rates of $44.4 \%$ and $16.2 \%$ at 6 and 12 months, respectively [11]. The secondary patency rates were $51.9 \%$ and $37 \%$ at 6 and 12 months, respectively. However, due to concerns when using stents, including fewer options for future surgery, they recommended stents for difficult stenoses [11]. Go et al. [9] investigated surgical revision and a hybrid strategy in thrombosed grafts, and found that graft salvage may be difficult when a stent is already present at the venous anastomosis site. Further studies are needed to evaluate the long-term benefits of stent-grafts for venous anastomosis site stenosis of AVGs.

The NKF-K/DOQI guidelines recommend the preparation of dialysis access for cannulation when initiating planned dialysis, as well as the use of a central venous catheter in the opposite extremity to achieve arteriovenous access, if necessary [1,26]. These guidelines aim to avoid the use of a central venous catheter because a strong association has been shown between central venous stenosis or occlusive disease and previous placement of a central venous catheter [26]. At our center, a central vein stent was implanted for central venous stenoses in which balloon angioplasty failed or recurred early after successful balloon angioplasty. Multivariate Cox regression analysis revealed that an existing central vein stent was a negative predictor of secondary patency, which supports the present guidelines.

A few limitations of this study should be discussed. First, this was a retrospective nonrandomized, single-institutional study. Second, different patient periods were present between the 2 groups; however, this limitation was inherent to the study design. Third, intragraft curettage was performed based on each surgeon's intraoperative decision without definite criteria, which could have affected the results of this study.

In conclusion, a hybrid strategy could be an option to salvage a thrombosed AVG with clinical evidence of a stenotic lesion. Intragraft curettage could also be beneficial, 
with a low complication rate, for relieving intragraft stenosis due to neointimal hyperplasia.

\section{Conflicts of interest}

No potential conflicts of interest relevant to this article are reported.

\section{ORCID}

You Kyeong Park: https://orcid.org/0000-0002-8306-7627 Jae Woong Lim: https://orcid.org/0000-0003-4512-0236

Chang Woo Choi: https://orcid.org/0000-0002-8042-7447

Keun Her: https://orcid.org/0000-0001-7824-1988

Hwa Kyun Shin: https://orcid.org/0000-0003-2078-5098

Sung Ho Shinn: https://orcid.org/0000-0001-9539-7941

\section{References}

1. Lok CE, Huber TS, Lee T, et al. KDOQI clinical practice guideline for vascular access: 2019 update. Am J Kidney Dis 2020;75(Suppl 2):S1-164.

2. Lim JW, Won YS, Kim DH, Shin HK. Comparative analysis of surgical thrombectomy with revision and percutaneous thrombectomy with angioplasty for treating obstruction of a dialysis graft. Korean $\mathrm{J}$ Thorac Cardiovasc Surg 2009;42:487-91.

3. Chan N, Wee I, Soong TK, Syn N, Choong AM. A systematic review and meta-analysis of surgical versus endovascular thrombectomy of thrombosed arteriovenous grafts in hemodialysis patients. J Vasc Surg 2019;69:1976-88.

4. Green LD, Lee DS, Kucey DS. A metaanalysis comparing surgical thrombectomy, mechanical thrombectomy, and pharmacomechanical thrombolysis for thrombosed dialysis grafts. J Vasc Surg 2002;36: 939-45.

5. Littler P, Cullen N, Gould D, Bakran A, Powell S. AngioJet thrombectomy for occluded dialysis fistulae: outcome data. Cardiovasc Intervent Radiol 2009;32:265-70.

6. Lajvardi A, Trerotola SO, Strandberg JD, Samphilipo MA, Magee C. Evaluation of venous injury caused by a percutaneous mechanical thrombolytic device. Cardiovasc Intervent Radiol 1995;18:172-8.

7. Dougherty MJ, Calligaro KD, Schindler N, Raviola CA, Ntoso A. Endovascular versus surgical treatment for thrombosed hemodialysis grafts: a prospective, randomized study. J Vasc Surg 1999;30:101623.

8. Bachleda P, Janeckova J, Xinopulos P, Smakal O. New hybrid procedures in treating occluded arteriovenous hemodialysis grafts. Biomed Pap Med Fac Univ Palacky Olomouc Czech Repub 2016;160:14952.

9. Go C, Kulkarni R, Wagner JK, et al. Comparable patency of open and hybrid treatment of venous anastomotic lesions in thrombosed haemodialysis grafts. Eur J Vasc Endovasc Surg 2020;60:897-903.

10. Kuhan G, Antoniou GA, Nikam M, et al. A meta-analysis of randomized trials comparing surgery versus endovascular therapy for thrombosed arteriovenous fistulas and grafts in hemodialysis. Cardiovasc Intervent Radiol 2013;36:699-705.

11. Calsina L, Clara A, Collado S, Barbosa F, Martinez R, Mateos E. Treatment of arteriovenous haemodialysis graft thrombosis associated to venous anastomotic stenosis by surgical thrombectomy, covered stenting and high-pressure angioplasty. Nefrologia 2013;33:56470.

12. Kakisis JD, Avgerinos E, Giannakopoulos T, Moulakakis K, Papapetrou A, Liapis CD. Balloon angioplasty vs nitinol stent placement in the treatment of venous anastomotic stenoses of hemodialysis grafts after surgical thrombectomy. J Vasc Surg 2012;55:472-8.

13. Sidawy AN, Gray R, Besarab A, et al. Recommended standards for reports dealing with arteriovenous hemodialysis accesses. J Vasc Surg 2002;35:603-10.

14. Ravani P, Quinn RR, Oliver MJ, et al. Pre-emptive correction for haemodialysis arteriovenous access stenosis. Cochrane Database Syst Rev 2016;2016:CD010709.

15. Roberts AC, Valji K, Bookstein JJ, Hye RJ. Pulse-spray pharmacomechanical thrombolysis for treatment of thrombosed dialysis access grafts. Am J Surg 1993;166:221-6.

16. Beathard GA. Mechanical versus pharmacomechanical thrombolysis for the treatment of thrombosed dialysis access grafts. Kidney Int 1994;45:1401-6.

17. Liu YH, Hung YN, Hsieh HC, Ko PJ. Surgical thrombectomy for thrombosed dialysis grafts: comparison of adjunctive treatments. World J Surg 2008;32:241-5.

18. Vascular Access Work Group. Clinical practice guidelines for vascular access. Am J Kidney Dis 2006;48 Suppl 1:S248-73.

19. Swedberg SH, Brown BG, Sigley R, Wight TN, Gordon D, Nicholls SC. Intimal fibromuscular hyperplasia at the venous anastomosis of PTFE grafts in hemodialysis patients: clinical, immunocytochemical, light and electron microscopic assessment. Circulation 1989;80: 1726-36.

20. Beathard GA. Percutaneous transvenous angioplasty in the treatment of vascular access stenosis. Kidney Int 1992;42:1390-7.

21. Tellis VA, Kohlberg WI, Bhat DJ, Driscoll B, Veith FJ. Expanded polytetrafluoroethylene graft fistula for chronic hemodialysis. Ann Surg 1979;189:101-5.

22. Bautista AB, Suhocki PV, Pabon-Ramos WM, Miller MJ Jr, Smith TP, Kim CY. Postintervention patency rates and predictors of patency after percutaneous interventions on intragraft stenoses within failing prosthetic arteriovenous grafts. J Vasc Interv Radiol 2015;26:1673-9.

23. Dolmatch B, Hogan A, Ferko N. An economic analysis of stent grafts for treatment of vascular access stenosis: point-of-care and medicare perspectives in the United States. J Vasc Interv Radiol 2018;29:765- 
73.

24. Kouvelos GN, Spanos K, Antoniou GA, et al. Balloon angioplasty versus stenting for the treatment of failing arteriovenous grafts: a meta-analysis. Eur J Vasc Endovasc Surg 2018;55:249-56.

25. Vesely T, DaVanzo W, Behrend T, Dwyer A, Aruny J. Balloon angio- plasty versus Viabahn stent graft for treatment of failing or thrombosed prosthetic hemodialysis grafts. J Vasc Surg 2016;64:1400-10.

26. Kundu S. Review of central venous disease in hemodialysis patients. J Vasc Interv Radiol 2010;21:963-8. 